\title{
Consensus channelome of dinoflagellates revealed by transcriptomic analysis sheds light on their physiology
}

\author{
Ilya Pozdnyakov*, Olga Matantseva and Sergei Skarlato \\ Institute of Cytology, Russian Academy of Sciences, St. Petersburg 194064, Russia
}

Ion channels are membrane protein complexes mediating passive ion flux across the cell membranes. Every organism has a certain set of ion channels that define its physiology. Dinoflagellates are ecologically important microorganisms characterized by effective physiological adaptability, which backs up their massive proliferations that often result in harmful blooms (red tides). In this study, we used a bioinformatics approach to identify homologs of known ion channels that belong to 36 ion channel families. We demonstrated that the versatility of the dinoflagellate physiology is underpinned by a high diversity of ion channels including homologs of animal and plant proteins, as well as channels unique to protists. The analysis of 27 transcriptomes allowed reconstructing a consensus ion channel repertoire (channelome) of dinoflagellates including the members of 31 ion channel families: inwardly-rectifying potassium channels, two-pore domain potassium channels, voltage-gated potassium channels $\left(\mathrm{K}_{\mathrm{v}}\right)$, tandem $\mathrm{K}_{v}$ cyclic nucleotide-binding domain-containing channels (CNBD), tandem CNBD, eukaryotic ionotropic glutamate receptors, large-conductance calcium-activated potassium channels, intermediate/small-conductance calcium-activated potassium channels, eukaryotic single-domain voltage-gated cation channels, transient receptor potential channels, two-pore domain calcium channels, four-domain voltage-gated cation channels, cation and anion Cys-loop receptors, small-conductivity mechanosensitive channels, large-conductivity mechanosensitive channels, voltage-gated proton channels, inositole-1,4,5trisphosphate receptors, slow anion channels, aluminum-activated malate transporters and quick anion channels, mitochondrial calcium uniporters, voltage-dependent anion channels, vesicular chloride channels, ionotropic purinergic receptors, animal volage-insensitive cation channels, channelrhodopsins, bestrophins, voltage-gated chloride channels $\mathrm{H}^{+} / \mathrm{Cl}^{-}$exchangers, plant calcium-permeable mechanosensitive channels, and trimeric intracellular cation channels. Overall, dinoflagellates represent cells able to respond to physical and chemical stimuli utilizing a wide range of Gprotein coupled receptors- and $\mathrm{Ca}^{2+}$-dependent signaling pathways. The applied approach not only shed light on the ion channel set in dinoflagellates, but also provided the information on possible molecular mechanisms underlying vital cellular processes dependent on the ion transport.

Key Words: channelome; dinoflagellates; ion channels; transcriptomes

Abbreviations: ALMT, aluminum-activated malate transporters and quick anion channels; BK, large-conductance calcium-activated potassium channels; CatSper, cation channels of sperm; CLC, voltage-gated chloride channels $\mathrm{H}^{+} /$ $\mathrm{Cl}^{-}$exchangers; CLIC, vesicular chloride channels; CNBD, cyclic nucleotide-binding domain-containing channels; 2xCNBD, tandem cyclic nucleotide-binding domain-containing channels; DEG/ENaC, animal volage-insensitive cation channels; EukCat, eukaryotic single-domain voltage-gated cation channels; FVCC, four-domain voltage-gated cation channels; GPCR, G-protein coupled receptors; $H_{v}$, voltage-gated proton channels; iGluR, eukaryotic ionotropic gluta-

(1) \$ This is an Open Access article distributed under the terms of the Creative Commons Attribution Non-Commercial License (http://creativecommons.org/licenses/by-nc/3.0/) which permits unrestricted non-commercial use, distribution, and reproduction in any medium, provided the original work is properly cited.
Received August 6, 2021, Accepted December 2, 2021

*Corresponding Author

E-mail: pozdnyakov@incras.ru

Tel: +7-812-297-18-29, Fax: +7-812-297-35-41 
mate receptors; IK/SK, intermediate/small-conductance calcium-activated potassium channels; $\mathrm{IP}_{3} \mathrm{R}$, inositole-1,4,5trisphosphate receptors; $\mathrm{K}_{2 \mathrm{~B}}$ two-pore domain potassium channels; $\mathrm{K}_{\mathrm{ir}}$, inwardly-rectifying potassium channels; $\mathrm{K}_{v}$, voltage-gated potassium channels; $2 \mathrm{xK}_{v}$, tandem voltage-gated potassium channels; MCA, plant calcium-permeable mechanosensitive channels; MCU, mitochondrial calcium uniporters; MscL, large-conductivity mechanosensitive channels; MscS, small-conductivity mechanosensitive channels; $\mathrm{Na}_{v} \mathrm{Bac}$, prokaryotic voltage-gated sodium/calcium channels; P2XR, ionotropic purinergic receptors; SDC, single domain channels; SLAC/SLAH, slow anion channels; TPC, two-pore domain calcium channels; TRIC, trimeric intracellular cation channels; TRP, transient receptor potential channels; VDAC, voltage-dependent anion channels

\section{INTRODUCTION}

Dinoflagellates are single-celled eukaryotes inhabiting marine and freshwater environments all over the globe. These protists play a tremendous role in ecosystems as both primary producers and consumers (Saldarriaga and Taylor 2017) due to their mixotrophic abilities (Burkholder et al. 2008). They are often responsible for major harmful algal blooms (red tides) in the coastal sea waters worldwide that deteriorate aquatic ecosystems, flora and fauna, aquaculture, fisheries, tourism and human health (Skarlato et al. 2018, Anderson et al. 2019, Khanaychenko et al. 2019, Glibert 2020, Telesh et al. 2021). The physiology of such environmentally significant organisms is a key to understanding the aquatic ecosystem functioning and their multidirectional responses to the changing environmental conditions due to accelerating natural and human-mediated stressors.

Interactions of an organism and the environment, including signal perception and transduction, imply the activity of ancient membrane proteins-ion channels. Ion channels are the major mediators of ion transport across biological membranes tightly involved in the formation of the resting and action potential, which, in turn, defines active transmembrane transport of nutrients, cell movement and other pivotal physiological processes (Hille 2001). Given their importance, ion channels are relatively well studied proteins with about 40 characterized protein families. Some of them are homologous to each other and constitute ion channel superfamilies, such as superfamilies of P-loop channels (voltage-gated cation channels) and Cys-loop receptors (Tikhonov and Zhorov 2005, Yu et al. 2005, Jaiteh et al. 2016).

Nevertheless, the information about ion channels gathered so far originates mainly from the studies of metazoan animals and plants. Other groups of eukaryotes are considerably less investigated in this respect and dinoflagellates are not an exception (Martinac et al. 2008). However, there are certain indications that these organisms possess numerous and diverse ion channels. Previously, it was shown that dinoflagellates Prorocentrum cordatum (syn. P. minimum) possess most of the animal-type voltage-gated cation channels (Pozdnyakov and Skarlato 2015). Furthermore, the study of a diversity of four-domain channels (FVCC) in eukaryotes indicated that the high diversity of these channels in dinoflagellates is comparable to that of animals (Pozdnyakov et al. 2018). Moreover, a recent study of a diversity of the voltage-gated potassium channels $\left(\mathrm{K}_{\mathrm{v}}\right)$ and cyclic-nucleotide domain-containing (CNBD) channels revealed unusual families of the tandem potassium channels $\left(2 \mathrm{xK}_{\mathrm{v}}\right)$ and tandem CNBD channels (2xCNBD) in dinoflagellates (Pozdnyakov et al. 2020). Meanwhile, the knowledge about the ion channel set typical to dinoflagellates is still far from complete.

A set of all ion channels expressed in a certain cell type or an entire taxonomic group is often referred to as a channelome. The channelome concept was successfully applied to human cells aiming at a better understanding of their physiology, disease pathogenesis and perspective treatment targets in medical research (Barrett-Jolley et al. 2010, Wright et al. 2016, Mobasheri et al. 2019). In this work, we identified a consensus ion channel repertoire of 27 dinoflagellate transcriptomes available in the Marine Microbial Eukaryote Transcriptome Sequencing Project (MMETSP, Combined Assembles) (Keeling et al. 2014) in order to get the information about the multifaceted ionic transport and associated physiological processes in these ecologically significant microorganisms.

\section{MATERIALS AND METHODS}

\section{Search for homologs}

In order to identify ion channels expressed in dino- 
flagellates, amino acid sequences of the pore-forming subunits of eukaryotic and bacterial ion channels (Supplementary Table S1) were used as queries for BLASTp searches against translated transcriptomes from MMETSP database (Keeling et al. 2014). In total, 30 transcriptomes of dinoflagellates were analyzed. To verify the homology of the revealed sequences, they were subsequently aligned against Conserved Domains Database (https://www.ncbi.nlm.nih.gov/cdd/). Homologs of the target ion channels in various organisms were obtained from the NCBI non-redundant protein sequences database using BLASTp search. Transcriptomes of Alexandrium fundyense CCMP1719, Oxyrrhis marina CCMP1795, and Symbiodinium kawagutii CCMP2468 were found to be poor in data and therefore were excluded from the analysis.

\section{Multiple sequence alignment and phylogenetic tree inferences}

We randomly chose five ion channel families found in dinoflagellates in order to elucidate the phylogenetic heterogeneity within each of them by phylogenetic analysis. Retrieved amino acid sequences of dinoflagellates were aligned with their homologs found in other eukaryotic and prokaryotic organisms (Supplementary Tables S2-S6) using a multiple alignment program MAFFT 7 (Katoh et al. 2019). Then the most non-conservative positions were manually trimmed out from the obtained alignments in BioEdit (Hall 1999). The resulting alignments were used for the model selection using Bayesian information criterion and maximal likelihood phylogeny inferences by means of IQ-Tree (Nguyen et al. 2015). The obtained trees were used as starting trees in subsequent tree inferences with ultrafast bootstrapping (10,000 replicates) in CIPRES Science Gateway (https://www.phylo. org/). FigTree 1.4.2 (Rambaut and Drummond 2015) was used for the phylogenetic tree visualization.

\section{RESULTS AND DISCUSSION}

We searched dinoflagellate transcriptomes in order to check them for the presence of members of 36 ion channel families, which makes this work the most complete study of the ion channel repertoire in algae to date. The analysis of 27 transcriptomes revealed representatives of 31 families of ion channels (Table 1, Supplementary Table 57 ). The channelome of each transcriptome included from 16 to 22 families. There was no correlation between the dinoflagellate taxonomic position and the number of ion channel families.

We classified ion channel families into three groups according to their abundance in 27 dinoflagellate transcriptomes: 'pervasive' (detected in 19-27 transcriptomes), 'common' (detected in 10-18 transcriptomes), and 'rare' (detected in 1-9 transcriptomes). The 'pervasive' group included different P-loop channel families (potassium channels $K_{i r}, K_{2 p}, K_{v}, 2 x K_{v}$, and large-conductance calcium-activated potassium channels (BK), ionotropic glutamate receptors [iGluR], CNBD-channels, single domain voltage-gated $\mathrm{Na}^{+} / \mathrm{Ca}^{2+}$ channels [i.e., homologs of $\mathrm{Na}_{\mathrm{v}-}$ Bac, cation channels of sperm (CatSper), and eukaryotic single-domain voltage-gated cation (EukCat) channels], two-pore domain calcium channels (TPC), and FVCC), cationic and anionic Cys-loop ligand-gated ion channels, small-conductivity mechanosensitive channels (MscS), P2X receptors, light-gated channels channelrhodopsins, and voltage-gated chloride channels $\mathrm{H}^{+} / \mathrm{Cl}^{-}$exchangers (CLC) and bestrophins.

The 'common' group consisted of transient receptor potential channels (TRP) and 2xCNBD channels of P-loop superfamily, voltage-gated $\mathrm{H}^{+}$channels $\left(\mathrm{H}_{\mathrm{v}}\right), \mathrm{Ca}^{2+}$ channels of endoplasmic reticulum - inositole-1,4,5-trisphosphate receptors $\left(\mathrm{IP}_{3} \mathrm{R}\right)$, and vesicular chloride channels (CLIC). Homologs of intermediate/small-conductance calciumactivated potassium channels (IK/SK), large-conductivity mechanosensitive channels (MscL) and plant calciumpermeable mechanosensitive channels, mitochondrial calcium uniporters (MCU) and voltage-dependent anion channels (VDAC), plant anion channels SLAC/SLAH and aluminum-activated malate transporters and quick anion channels (ALMT), animal volage-insensitive cation channels (DEG/ENaC), $\mathrm{K}^{+}$channels of endoplasmic reticulum trimeric intracellular cation channels (TRIC) constituted the 'rare' group since they were found in 1-5 cases only, which indicates either specific conditions for their expression or contamination of the investigated transcriptomes. Members of ion channel families of the bacterial iGluRs, animal store-operated calcium channels Orai, mechanosensitive ion channels Piezo, proton channels Otopertins, and eukaryotic and prokaryotic potassium channels TMEM175 were not revealed in any dinoflagellate transcriptome. The absence of these ion channels in the investigated transcriptomes does not necessarily mean that they are indeed absent in dinoflagellates. There is always a possibility that sequencing and assembly errors or specific conditions required for the gene transcription result in the apparent lack of some transcripts. Nevertheless, most of ion channel families 


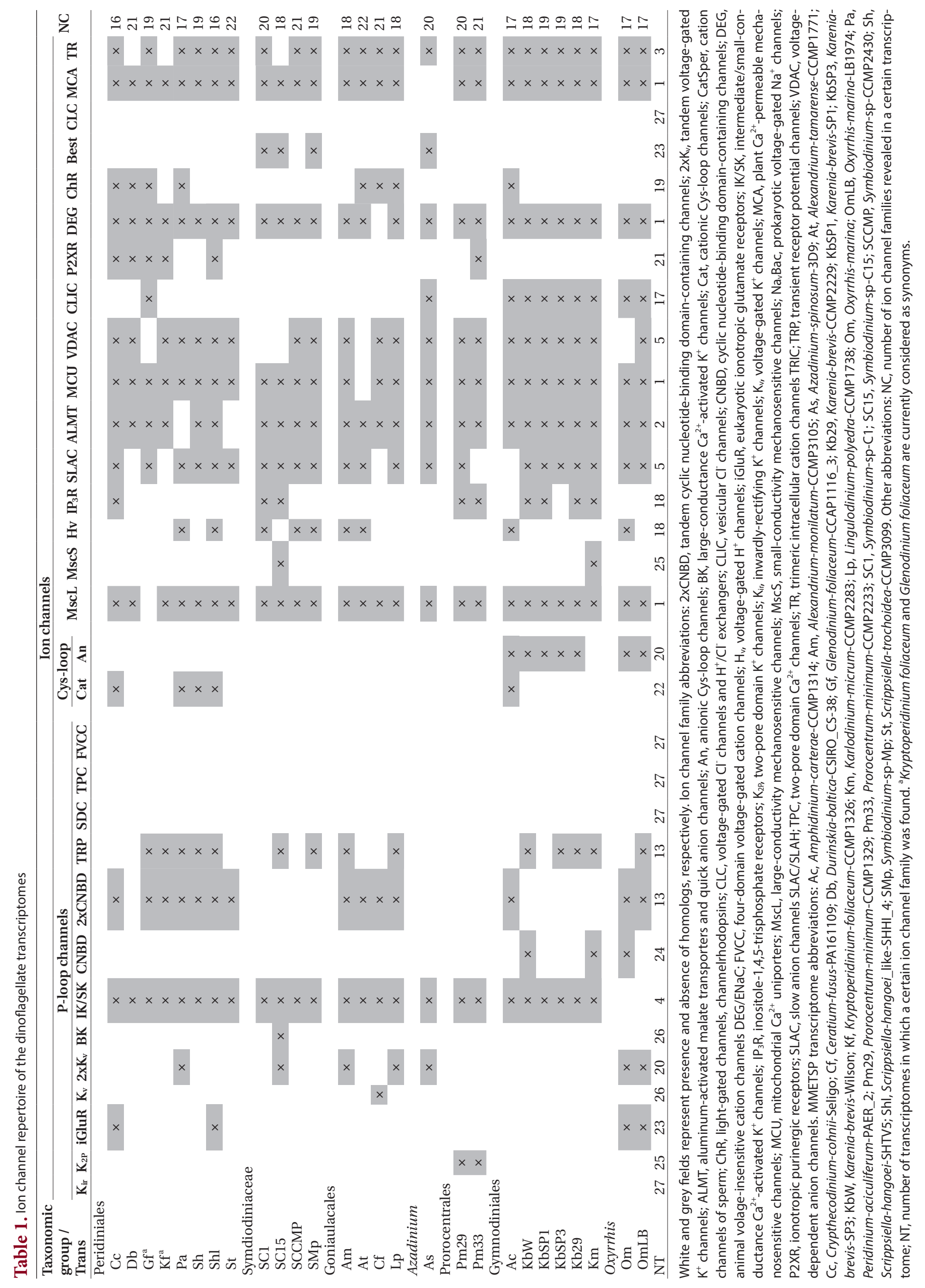


are present in a moderate to large number of the investigated dinoflagellate transcriptomes and, therefore, are likely a part of the essential molecular machinery used by these microorganisms.

Previously, we revealed the intrafamily phylogenetic diversity of FVCC channels of dinoflagellates and other eukaryotes (Pozdnyakov et al. 2018). Here we showed that the dinoflagellate ion channels from one family (bestrophins, $\mathrm{BK}, \mathrm{IP}_{3} \mathrm{R}, \mathrm{K}_{2 \mathrm{p}}$, and VDAC) did not form a single clade in all cases (Supplementary Fig. S1-S5). Such phylogenetic heterogeneity may reflect a functional diversity of the identified homologs.

\section{Membrane potential regulation}

Voltage difference across the cell membrane-a membrane potential-is an attribute of all living cells. Membrane potential is generated by the activity of ion channels and pumps and represents one of the major forms of energy storage in a cell. Therefore, membrane potential is a key factor in the active (energy-dependent) transmembrane transport of different chemical compounds, e.g., in osmotrophic nutrition. In addition, changes in the transmembrane voltage difference, such as the graded and action potentials, are utilized by a cell in the processes of signal reception and transduction, movement, contraction, and secretion control (Hille 2001, Taylor et al. 2012, Brunet and Arendt 2016).

Potassium channels are an important part of the membrane potential regulation system in many eukaryotes (Hille 2001, Martinac et al. 2008). It is highly probable that, similar to other organisms, dinoflagellates utilize the electrochemical gradient of $\mathrm{K}^{+}$for the membrane potential maintenance. Dinoflagellates possess various types of homologs of potassium channels. Among them, $\mathrm{K}_{\mathrm{ir}}$ and $\mathrm{K}_{2 \mathrm{P}}$ channels could be involved in the setting of the membrane potential, whereas voltage-gated potassium channels $\mathrm{K}_{\mathrm{v}}$ likely participate in the repolarization phase of the action potential as it happens in animal cells. The depolarization phase of the action potential is mediated by calcium channels FVCC in metazoans (Hille 2001), ciliates (Lodh et al. 2016), and green algae (Fujiu et al. 2009) and by the single-domain voltage-gated channels (EukCat homologs) in diatoms (Helliwell et al. 2019). In dinoflagellates, these channels could potentially play a similar role. However, this assumption is still to be tested empirically.

The only set of experimental data on changes in the membrane potential obtained for dinoflagellates relates to the species Noctiluca miliaris. The electrophysilogical investigations of $N$. miliaris demonstrated the presence of two types of electrical exitability. One type is the spontaneous non-propagated changes in the membrane potential that control movements of a food-gathering tentacle-and are known as a tentacle-regulating potential (Eckert and Sibaoka 1967, Sibaoka and Eckert 1967, Oami et al. 1988). These changes in potential occur on the tentacle membrane in two phases: depolarization phase caused by the opening of $\mathrm{Ca}^{2+}$-dependent $\mathrm{Na}^{+}$channels, and hyperpolarizing phase caused by the opening of $\mathrm{Cl}^{-}$ channels (Eckert and Sibaoka 1967, Oami et al. 1988). Although the molecular nature of these channels still has to be unveiled, we assume that the sodium current could be theoretically attributed to FVCC channels, since their homologs in dinoflagellates possess $\mathrm{Ca}^{2+}$-binding domains as it was revealed by the in silico analysis (Pozdnyakov et al. 2018). In this work, we also identified several $\mathrm{Cl}^{-}$channels including voltage-gated CLC channels that could theoretically participate in the hyperpolarization phase of the tentacle-regulating potential.

The second type of exitability in N. miliaris is a socalled flash-triggering potential, which controls bioluminescence events. Notably, this all-or-none action potential develops not on the plasma membrane, but on the inner vacuolar membrane system and is mediated by $\mathrm{H}^{+}$current through the voltage-gated proton channels (Eckert 1965, Eckert and Sibaoka 1968, Nawata and Sibaoka, 1979, see section Proton transport and bioluminescence).

\section{Calcium signaling system}

Calcium ions modulate the activity of $\mathrm{Ca}^{2+}$-binding proteins found in all living organisms and represent the only secondary messenger of ionic nature connecting electrical and chemical signaling pathways in a cell. Many cellular processes depend on oscillations of the intracellular $\mathrm{Ca}^{2+}$ concentration, among them are endoand exocytosis, movement, signal transduction, gene expression, proliferation, apoptosis, etc. (Berridge et al. 2003, Dominguez 2004).

Calcium signaling system functioning depends on the variety of ion channels localized in different cellular compartments, including the plasma membrane and membranes of mitochondria, endoplasmic reticulum, and intracellular vesicles (Berridge et al. 2003). The analysis of dinoflagellate transcriptomes revealed several families of the plasma membrane $\mathrm{Ca}^{2+}$ channels activated by different stimuli:TRP, single-domain channels, and FVCC. Moreover, we found $\mathrm{Ca}^{2+}$-activated $\mathrm{K}^{+}$channels BK 
in 26 transcriptomes and IK/SK in three transcriptomes out of 27. BK and IK/SK channels are known to mediate potassium efflux in response to the increasing cytosolic $\mathrm{Ca}^{2+}$ concentration ensured by the plasma membrane calcium channels, thus representing an integrated system (Kaczmarek et al. 2017). In animals, the cytosolic calcium concentration can also be elevated as a result of the store-operated calcium entry through Orai channels (Lopez et al. 2020); however, we did not discover these proteins in any dinoflagellate transcriptome.

An increase in the cytosolic calcium level can be mediated by $\mathrm{Ca}^{2+}$ channels of the intracellular calcium stores, for example, $\mathrm{IP}_{3}$ receptors of the endoplasmic reticulum, TPC channels localized in vesicle membranes, and MCU and VDAC channels of mitochondrial membranes (Berridge et al. 2003). Only $\mathrm{IP}_{3}$ channels were widely spread in the analyzed transcriptomes (18/27); therefore, we assume that the endoplasmic reticulum is the main calcium store in a dinoflagellate cell. Nevertheless, similar to other alveolates, dinoflagellates possess a specific cell covering comprising the plasma membrane underlined by the so-called amphiesmal vesicles (Pozdnyakov and Skarlato 2012). Ciliates that represent another group of alveolates have a similar (homologous) structure of their cell covering including cortical vesicles (also known as alveolar sacs). These vesicles function as $\mathrm{Ca}^{2+}$ stores in ciliates (Stelly et al. 1991) and even possess $\mathrm{IP}_{3} \mathrm{R}$-like channels (Plattner 2014). We assume that the amphiesmal vesicles of dinoflagellates can function in a similar way and participate in $\mathrm{Ca}^{2+}$ release and buffering. Moreover, the endoplasmic reticulum potassium channels of TRIC family were also found, but only in three cases. In animal cells, TRIC channels are known to mediate $\mathrm{K}^{+}$influx from the cytosole to the endoplasmic reticulum lumen ensuring sufficient electrogenic force for $\mathrm{Ca}^{2+}$ efflux through $\mathrm{IP}_{3}$ Rs (Yazawa et al. 2007).

Recently, Guo et al. (2021) demonstrated the role of the calcium signaling and $\mathrm{Ca}^{2+}$ transport proteins in the formation of pellicle cysts of Scrippsiella trochoidea in response to cold and darkness.

\section{Extracellular chemical signal transduction}

Behavior of unicellular organisms is affected by different chemical signals present in the environment (Cembella 2003). Perception of such signals relies on the functioning of specific receptors and downstream signal transduction pathways. Ligand-gated ion channels (i.e., ionotropic receptors) and ion channels regulated by secondary messengers or by signaling proteins are often in- tegrated in the receptor signaling systems.

Here we demonstrated the presence of several families of ligand-gated ion channels in dinoflagellates. Cysloop receptors representing cation or anion ligand-gated channels are widely distributed among the dinoflagellate transcriptomes. In animals, these channels are known to be activated by small molecules, such as acetylcholine, gamma aminobutyric acid, glycine, and serotonin (Jaiteh et al. 2016). Therefore, we assume that these channels could play a role of small molecule sensors detecting, for instance, free dissolved amino acids serving as nitrogen substrates for these organisms (Dagenais-Bellefeuille and Morse 2013, Matantseva et al. 2018). iGluRs and P2X receptors that were also found in many dinoflagellate transcriptomes could play a similar role linking such stimuli to the calcium signaling pathways. In animals, ionotropic receptors are also targets for the action of various secondary metabolites. Dinoflagellates produce a vast diversity of such compounds likely involved in the regulation of their activity (Cembella 2003). Therefore, the channels listed above could also function as secondary metabolite receptors and play a central role in the chemical interactions of dinoflagellates with other organisms of the same and different species. All these assumptions require the experimental confirmation or rebuttal.

In addition, homologs of channels that can be activated by the secondary messengers, e.g., by cyclic nucleotides and $\mathrm{Ca}^{2+}$, were also found to be expressed in dinoflagellates. In other organisms, such channels are usually integrated in the signal transduction systems where perception of chemical stimuli is mediated by G-protein coupled receptors (GPCRs) (Hilger et al. 2018). On the one hand, activation of GPCRs can lead to the activation of $\mathrm{G} \alpha$ proteins and adenylate/guanylate cyclase leading to a subsequent increase in the concentration of cyclic nucleotides in the cytosol. Cyclic nucleotides are the secondary messengers binding to CNBD-channels and opening them. On the other hand, activation of GPCRs coupled to Gs proteins results in the inhibition of adenylate/guanylate cyclase and CNBD-channel closure, thus imposing an opposite effect on a cell (Craven and Zagotta 2006). In both cases, the membrane potential changes in response to the receptor activation.

Another class of $\mathrm{G}$ proteins-Gq-containing proteinscouple GPCRs with phospholipase $\mathrm{C}$ and promote the formation of two types of the secondary messengers: inositole-1,4,5-trisphospate $\left(\mathrm{IP}_{3}\right)$ and diacylglycerol. $\mathrm{IP}_{3}$ interacts with its receptors $\mathrm{IP}_{3} \mathrm{R}$, which leads to the calcium store depletion. This signaling pathway was found to be involved in the melatonin-induced encystment of 
the dinoflagellate Alexandrium catenella in laboratory experiments (Tsim et al. 1997). Besides gating of channels mediated by secondary messengers, G-proteins are known to regulate the gating of $K_{\text {ir }}$ channels in animals indicating that $\mathrm{K}_{\mathrm{ir}}$ channels of dinoflagellates could be regulated in a similar way.

\section{Mechanical sensing}

All living cells are influenced by mechanical stimuli. Several families of ion channels that are involved in mechanosensing in bacteria, animals and other eukaryotes were revealed in dinoflagellates. Among them, MscS, TRP, and $\mathrm{K}_{2 \mathrm{P}}$ channels were present in most of the analyzed transctiptomes, whereas each of MscL and DEG/ $\mathrm{ENaC}$ homologs was detected only in one transcriptome. Bioluminescent dinoflagellates can activate the luciferase reaction, which backs up their glowing in response to the mechanical impact (Eckert and Sibaoka 1968). In addition, mechanical stress can induce ecdysis, the cell covering rearrangement, in dinoflagellates (Berdieva et al. 2019, Matantseva et al. 2020). Mechanosensitive ion channels are probably involved in the initiation of this process and also the processes of encystment and excystment associated with the reorganization of cell covering.

\section{Photoreception}

Many dinoflagellates are capable of phototaxis and possess different types of eyespots representing modified chloroplasts (Horiguchi et al. 1999). Therefore, it was not a surprise to find the channelrhodopsin homologs in many dinoflagellate transcriptomes. It is remarkable, however, that homologs of the light-gated channels were found in the transcriptomes of heterotrophic species (Crypthecodinium cohnii and Oxyrrhis marina). These proteins are the light-gated $\mathrm{Na}^{+} / \mathrm{Ca}^{2+} / \mathrm{H}^{+}$channels in prokaryotes and some algae (Schneider et al. 2015). Moreover, the light-gated ion channels probably take part in the control of diurnal rhythms affecting various aspects of the dinoflagellate physiology (Van Dolah et al. 2007, Hastings 2013). Genes encoding proteins similar to proteorhodopsin were found in the dinoflagellate Pyrocystis lunula and were proposed as a part of the system of circadian rhythm regulation (Okamoto and Hastings 2003).

\section{Proton transport and bioluminescence}

As mentioned above, some dinoflagellate species are capable of bioluminescence caused by the luciferase re- action taking place in the special cellular compartmentsscintillons. This process is under the electrical control of voltage-gated $\mathrm{H}^{+}$channels (Eckert 1965, Eckert and Sibaoka 1968). $\mathrm{H}_{\mathrm{v}}$ channels of the dinoflagellates Karlodinium veneficum and Lingulodinium polyedrum were recently characterized experimentally (Smith et al. 2011, Rodrigues et al. 2017).

Previously, we identified $\mathrm{H}_{\mathrm{v}}$ transcripts in the transcriptomes of the non-luminescent dinoflagellate Prorocentrum cordatum (Pozdnyakov and Skarlato 2015). Then, the presence of $\mathrm{H}_{\mathrm{v}}$ channels in the core and basal dinoflagellate lineages was shown by Kigundu et al. (2018). In that study, the authors reported the presence of $\mathrm{H}_{\mathrm{v}}$ channels not only in bioluminescent dinoflagellates but also in 23 non-luminescent species. Obviously, the physiological role of $\mathrm{H}_{\mathrm{v}}$ channels is not limited to the control of bioluminescence. Proton channels are known to be abundant in different evolutionary algal lineages (Taylor et al. 2012), participating in $\mathrm{pH}$-homeostasis at least in some of them (Taylor et al. 2011).

\section{Anion and nutrient transport}

Our analysis revealed a variety of anion channels with different modes of gating. Among them, voltage-gated chloride channels CLC, calcium-activated bestrophins, ligand-gated Cys-loop receptors, and vesicular CLIC were the most abundant. Remarkably, such ion channels as CLC, ALMT, and SLAC are known to be involved in the nitrate transport in plant cells (Krapp et al. 2014, Sharma et al. 2016). At the same time, bestrophins mediate $\mathrm{HCO}_{3}{ }^{-}$ transport into thylakoids in green algae (Mukherjee et al. 2019). Therefore, the consensus channelome not only shows the pathways for electrical and signaling events, but also reveals plausible gates for dinoflagellate nutrition.

\section{CONCLUSION}

Motility and a complex cell covering make most dinoflagellates challenging objects for electrophysiological studies of ion channels requiring the development of new experimental approaches (Pozdnyakov et al. 2014). As a result, until recently, the knowledge about ion channels in these organisms has been limited to a modest number of pioneering research works and a few types of ion channels. A bioinformatics approach applied in this work not only shed light on the ion channel repertoire in dinoflagellates, but also provided the information on 


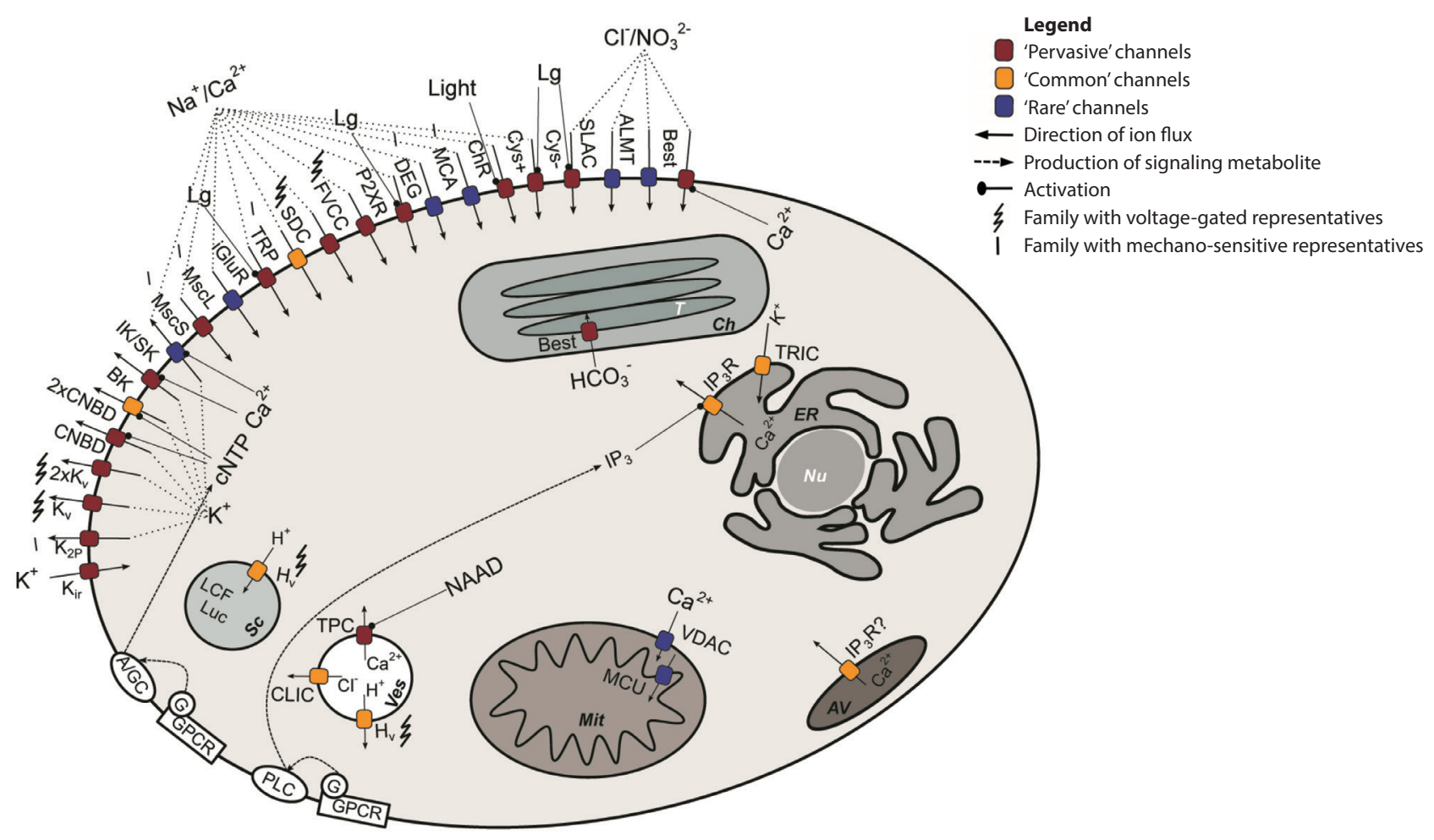

Fig. 1. Consensus ion channel repertoire of dinoflagellates. In this conceptual scheme, ion channels found in at least one dinoflagellate transcriptome, as well as putative links between ionic transport and cell signaling are depicted. 'Pervasive' channels are found in 19-27 transcriptomes; 'Common' channels are found in 10-18 transcriptomes; 'Rare' channels are found in less than 10 transcriptomes. lon channel family abbreviations: $2 \times C N B D$, tandem cyclic nucleotide-binding domain-containing channels; $2 \mathrm{KK}_{\mathrm{v}}$, tandem voltage-gated $\mathrm{K}^{+}$channels; ALMT, aluminum-activated malate transporters and quick anion channels; BK, large-conductance $\mathrm{Ca}^{2+}$-activated $\mathrm{K}^{+}$channels; ChR, light-gated channels, channelrhodopsins; CLIC, vesicular $\mathrm{Cl}^{-}$channels; CNBD, cyclic nucleotide-binding domain-containing channels; Cys-, anionic Cys-loop channels; Cys+, cationic Cys-loop channels; DEG, animal volage-insensitive cation channels DEG/ENaC; FVCC, four-domain voltage-gated cation channels; $\mathrm{H}_{\mathrm{v}}$, voltage-gated $\mathrm{H}^{+}$channels; iGluR, eukaryotic ionotropic glutamate receptors; IK/SK, intermediate/small-conductance $\mathrm{Ca}^{2+}$-activated $\mathrm{K}^{+}$channels;

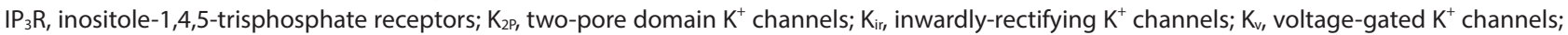
$\mathrm{MCA}$, plant $\mathrm{Ca}^{2+}$-permeable mechanosensitive channels; $\mathrm{MCU}$, mitochondrial $\mathrm{Ca}^{2+}$ uniporters; $\mathrm{MscL}$, large-conductivity mechanosensitive channels; MscS, small-conductivity mechanosensitive channels; P2XR, ionotropic purinergic receptors; SLAC, slow anion channels SLAC/SLAH; TPC, two-pore domain $\mathrm{Ca}^{2+}$ channels; TRP, transient receptor potential channels; VDAC, voltage-dependent anion channels. Other abbreviations: A/GC, adenylate or guanylate cyclase; $A V$, amphiesmal vesicle; $C h$, chloroplast; CNTP, cyclic nucleotide; $E R$, endoplasmic reticulum; G, G-protein; GPCR, G-protein coupled receptor; $\mathrm{IP}_{3}$, inositole-1,4,5-trisphosphate; LCF, luciferase; Lg, ligand; Luc, luciferin; Mit, mitochondrion; NAAD, nicotinic acid adenine dinucleotide; Nu, nucleus; PLC, phospholipase C; Sc, scintillon; T, thylakoid; Ves, vesicle; ?, putative.

possible molecular mechanisms underlying cellular processes dependent on the ion transport. This information is indispensable for addressing a variety of questions regarding the physiology of dinoflagellates and their environmental impact experimentally.

Dinoflagellates are characterized by a broad range of adaptive strategies including various modes of nutrition, resistance to the changes in salinity, vertical migration and more. They deploy specific reactions in response to stress conditions, such as ecdysis and the formation of cysts (Pozdnyakov and Skarlato 2012, Matantseva et al. 2020). Understanding fine mechanisms of these processes is crucial for the future predictions of harm- ful dinoflagellate blooms and combatting red tides. Our study demonstrated that the versatility of the dinoflagellate physiology is underpinned by a high diversity of ion channels including homologs of animal and plant proteins, as well as channels unique to protists. Each of the physiological processes mentioned above could be backed up by particular ion channel types identified in this work, but experimental data are still scarce. Overall, from the standpoint of ionic transport, dinoflagellates represent cells capable of responding to physical and chemical stimuli by utilizing a wide range of GPCR- and $\mathrm{Ca}^{2+}$-dependent signaling pathways (Fig. 1). The abundance of such channels as FVCC, EukCat, and $\mathrm{K}_{\mathrm{v}}$ suggests 
membrane excitability and the ability to generate action potentials in many species. We anticipate that the results presented in this study would encourage the so far deficient experimental investigations in this field.

\section{ACKNOWLEDGEMENTS}

The research was funded by the Russian Science Foundation, project 19-14-00109. The English language was checked by the Effective Language Tutoring Services.

\section{CONFLICTS OF INTEREST}

The authors declare that they have no potential conflicts of interest.

\section{SUPPLEMENTARY MATERIALS}

Supplementary Table S1. List of amino acid sequences used as queries in BLASTp searches (https://www.e-algae.org).

Supplementary Table S2. List of amino acid sequences used in the phylogenetic analysis of bestrophins (https:// www.e-algae.org).

Supplementary Table S3. List of amino acid sequences used in the phylogenetic analysis of large-conductance calcium-activated potassium channels (BK) (https:// www.e-algae.org).

Supplementary Table S4. List of amino acid sequences used in the phylogenetic analysis of inositole-1,4,5-trisphosphate receptors $\left(\mathrm{IP}_{3} \mathrm{R}\right)$ (https://www.e-algae.org).

Supplementary Table S5. List of amino acid sequences used in the phylogenetic analysis of two-pore domain potassium channels $\left(K_{2 \mathrm{p}}\right)$ (https://www.e-algae.org).

Supplementary Table S6. List of amino acid sequences used in the phylogenetic analysis of voltage-dependent anion channels (VDAC) (https://www.e-algae.org).

Supplementary Table S7. The best results of BLASTp search in the translated combined assembles of dinoflagellate transcriptomes in marine microbial eukaryote transcriptome sequencing project (MMETSP) (https:// www.e-algae.org).

Supplementary Fig. S1. Maximal likelihood inference of unrooted phylogenetic tree (LG + F + R3, 10,000 ultrafast bootstrap replicates, bootstrap values $<60$ are not shown) of bestrophins (https://www.e-algae.org).

Supplementary Fig. S2. Maximal likelihood inference of unrooted phylogenetic tree (LG + F + R5, 10,000 ultrafast bootstrap replicates, bootstrap values $<60$ are not shown) of large-conductance calcium-activated potassium channels (BK) (https://www.e-algae.org).

Supplementary Fig. S3. Maximal likelihood inference of unrooted phylogenetic tree $(\mathrm{LG}+\mathrm{I}+\Gamma 4,10,000$ ultrafast bootstrap replicates, bootstrap values $<60$ are not shown) of inositole-1,4,5-trisphosphate receptors $\left(\mathrm{IP}_{3} \mathrm{R}\right)$ (https://www.e-algae.org).

Supplementary Fig. S4. Maximal likelihood inference of unrooted phylogenetic tree (LG + F + R4, 10,000 ultrafast bootstrap replicates, bootstrap values $<60$ are not shown) of of two-pore domain potassium channels $\left(\mathrm{K}_{2 \mathrm{p}}\right)$ (https://www.e-algae.org).

Supplementary Fig. S5. Maximal likelihood inference of unrooted phylogenetic tree (LG + F + I + Г4, 10,000 ultrafast bootstrap replicates, bootstrap values $<60$ are not shown) of of voltage-dependent anion channels (VDAC) (https://www.e-algae.org).

\section{REFERENCES}

Anderson, C. R., Berdalet, E., Kudela, R. M., Cusak, C. K., Silke, J., O’Rourke, E., Dugan, D., McCammon, M., Newton, J. A., Moore, S. K., Paige, K., Ruberg, S., Morrison, J. R., Kirkpatrick, B., Hubbard, K. \& Morell, J. 2019. Scaling up from regional case studies to a global Harmful Algal Bloom observing system. Front. Mar. Sci. 6:250.

Barrett-Jolley, R., Lewis, R., Fallman, R. \& Mobasheri, A. 2010. The emerging chondrocyte channelome. Front. Physiol. 1:135.

Berdieva, M., Safonov, P. \& Matantseva, O. 2019. Ultrastructural aspects of ecdysis in naked dinoflagellate Amphidinium carterae. Protistology 13:57-63.

Berridge, M. J., Bootman, M. D. \& Roderick, H. L. 2003. Calcium signalling: dynamics, homeostasis and remodelling. Nat. Rev. Mol. Cell Biol. 4:517-529.

Brunet, T. \& Arendt, D. 2016. From damage response to action potentials: early evolution of neuronal and contractile modules in stem eukaryotes. Phil. Trans. R. Soc. Lond. B Biol. Sci. 371:20150043.

Burkholder, J. M., Glibert, P. M. \& Skelton, H. 2008. Mixotrophy, a major mode of nutrition for harmful algal species in eutrophic waters. Harmful Algae 8:77-93.

Cembella, A. D. 2003. Chemical ecology of eukaryotic microalgae in marine ecosystems. Phycologia 42:420-447.

Craven, K. B. \& Zagotta, W. N. 2006. CNG and HCN channels: two peas, one pod. Annu. Rev. Physiol. 68:375-401.

Dagenais-Bellefeuille, S. \& Morse, D. 2013. Putting the N in 
dinoflagellates. Front. Microbiol. 4:369.

Dominguez, D. C. 2004. Calcium signalling in bacteria. Mol. Microbiol. 54:291-297.

Eckert, R. 1965. Bioelectric control of bioluminescence in the dinoflagellate Noctiluca. I. Specific nature of triggering events. Science 147:1140-1142.

Eckert, R. \& Sibaoka, T. 1967. Bioelectric regulation of tentacle movement in a dinoflagellate. J. Exp. Biol. 47:433-446.

Eckert, R. \& Sibaoka, T. 1968. The flash-triggering act ion potential of the luminescent dinoflagellate Noctiluca. J. Gen. Physiol. 52:258-282.

Fujiu, K., Nakayama, Y., Yanagisawa, A., Sokabe, M. \& Yoshimura, K. 2009. Chlamydomonas CAV2 encodes a voltage-dependent calcium channel required for the flagellar waveform conversion. Curr. Biol. 19:133-139.

Glibert, P. M. 2020. Harmful algae at the complex nexus of eutrophication and climate change. Harmful Algae 91:101583.

Guo, X., Wang, Z., Liu, L. \& Li, Y. 2021. Transcriptome and metabolome analyses of cold and darkness-induced pellicle cysts of Scrippsiella trochoidea. BMC Genomics 22:526.

Hall, T. A. 1999. BioEdit: a user-friendly biological sequence alignment editor and analysis program for Windows 95/98/NT. Nucleic Acids Symp. Ser. 41:95-98.

Hastings, J. W. 2013. Circadian rhythms in dinoflagellates: what is the purpose of synthesis and destruction of proteins? Microorganisms 1:26-32.

Helliwell, K. E., Chrachri, A., Koester, J. A., Wharam, S., Verret, F., Taylor, A. R., Wheeler, G. L. \& Brownlee, C. 2019. Alternative mechanisms for fast $\mathrm{Na}^{+} / \mathrm{Ca}^{2+}$ signaling in eukaryotes via novel class of single-domain voltage-gated channels. Curr. Biol. 29:1503-1511.

Hilger, D., Masureel, M. \& Kobilka, B. K. 2018. Structure and dynamics of GPCR signaling complexes. Nat. Struct. Mol. Biol. 25:4-12.

Hille, B. 2001. Ion channels of excitable membranes. 3rd ed. Sinauer Associates, Sunderland, MA, 816 pp.

Horiguchi, T., Kawai, H., Kubota, M., Takahashi, T. \& Watanabe, M. 1999. Phototactic responses of four marine dinoflagellates with different types of eyespot and chloroplast. Phycol. Res. 47:101-107.

Jaiteh, M., Taly, A. \& Hénin, J. 2016. Evolution of pentameric ligand-gated ion channels: pro-loop receptors. PLoS ONE 11:e0151934.

Kaczmarek, L. K., Aldrich, R. W., Chandy, K. G., Grissmer, S., Wei, A. D. \& Wulff, H. 2017. International union of basic and clinical pharmacology. C. Nomenclature and properties of calcium-activated and sodium-activated potassium channels. Pharmacol. Rev. 69:1-11.
Katoh, K., Rozewicki, J. \& Yamada, K. D. 2019. MAFFT online service: multiple sequence alignment, interactive sequence choice and visualization. Brief. Bioinform. 20:1160-1166.

Keeling, P. J., Burki, F., Wilcox, H. M., Allam, B., Allen, E. E., Amral-Zettler, L. A., Armbrust, E. V., Archibald, J. M., Bharti, A. K., Bell, C. J., Beszteri, B., Bidle, K. D., Cameron, C. T., Campbell, L., Caron, D. A., Cattolico, R. A., Collier, J. L., Coyne, K., Davy, S. K., Deschamps, P., Dyhrman, S. T., Edvardsen, B., Gates, R. D., Gobler, C. J., Greenwood, S. J., Guida, S. M., Jacobi, J. L., Jakobsen, K. S., James, E. R., Jenkins, B., John, U., Johnson, M. D., Juhl, A. R., Kamp, A., Katz, L. A., Kiene, R., Kudryavtsev, A., Leander, B. S., Lin, S., Lovejoy, C., Lynn, D., Marchetti, A., McManus, G., Nedelcu, A. M., Menden-Deuer, S., Miceli, C., Mock, T., Montresor, M., Moran, M. A., Murray, S., Nadathur, G., Nagai, S., Ngam, P. B., Palenik, B., Pawlowski, J., Petroni, G., Piganeau, G., Posewitz, M. C., Rengefors, K., Romano, G., Rumpho, M. E., Rynearson, T., Schilling, K. B., Schroeder, D. C., Simpson, A. G. B., Slamovits, C. H., Smith, D. R., Smith, G. J., Smith, S. R., Sosik, H. M., Stief, P., Theriot, E., Twary, S. N., Umale, P. E., Vaulot, D., Wawrik, B., Wheeler, G. L., Wilson, W. H., Xu, Y., Zingone, A. \& Worden, A. Z. 2014. The Marine Microbial Eukaryote Transcriptome Sequencing Project (MMETSP): illuminating the functional diversity of eukaryotic life in the oceans through transcriptome sequencing. PLoS Biol. 12:e1001889.

Khanaychenko, A. N., Telesh, I. V. \& Skarlato, S. O. 2019. Bloom-forming potentially toxic dinoflagellates Prorocentrum cordatum in marine plankton food webs. Protistology 13:95-125.

Kigundu, G., Cooper, J. L. \& Smith, S. M. E. 2018. H $_{v} 1$ proton channels in dinoflagellates: not just for bioluminescence? J. Eukaryot. Microbiol. 65:928-933.

Krapp, A., David, L. C., Chardin, C., Girin, T., Marmange, A., Leprince, A.-S., Chaillou, S., Ferrario-Méry, S., Meyer, C. \& Daniel-Vedele, F. 2014. Nitrate transport and signalling in Arabidopsis. J. Exp. Bot. 65:789-798.

Lodh, S., Yano, J., Valentine, M. S. \& Van Houten, J. L. 2016. Voltage-gated calcium channels of Paramecium cilia. J. Exp. Biol. 219:3028-3038.

Lopez, J. J., Jardin, I., Albarrán, L., Sanchez-Collado, J., Cantonero, C., Salido, G. M., Smani, T. \& Rosado, J. A. 2020. Molecular basis and regulation of store-operated calcium entry. Adv. Exp. Med. Biol. 1131:445-469.

Martinac, B., Saimi, Y. \& Kung, C. 2008. Ion channels in microbes. Physiol. Rev. 88:1449-1490.

Matantseva, O., Berdieva, M., Kalinina, V., Pozdnyakov, I., Pechkovskaya, S. \& Skarlato, S. 2020. Stressor-induced 
ecdysis and thecate cyst formation in the armoured dinoflagellates Prorocentrum cordatum. Sci. Rep. 10: 18322.

Matantseva, O., Pozdnyakov, I., Voss, M., Liskow, I. \& Skarlato, S. 2018. The uncoupled assimilation of carbon and nitrogen from urea and glycine by the bloomforming dinoflagellate Prorocentrum minimum. Protist 169:603-614.

Mobasheri, A., Matta, C., Uzielienè, I., Budd, E., Martín-Vasallo, P. \& Bernotiene, E. 2019. The chondrocyte channelome: a narrative review. Joint Bone Spine 86:29-35.

Mukherjee, A., Lau, C. S., Walker, C. E., Rai, A. K., Prejean, C. I., Yates, G., Emrich-Mills, T., Lemoine, S. G., Vinyard, D. J., Mackinder, L. C. M. \& Moroney, J. V. 2019. Thylakoid localized bestrophin-like proteins are essential for the $\mathrm{CO}_{2}$ concentrating mechanism of Chlamydomonas reinhardtii. Proc. Natl. Acad. Sci. U. S. A. 116:16915-16920.

Nawata, T. \& Sibaoka, T. 1979. Coupling between action potential and bioluminescence in Noctiluca: effects of inorganic ions and $\mathrm{pH}$ in vacuolar sap. J. Comp. Physiol. 134:137-149.

Nguyen, L. -T., Schmidt, H. A., Von Haeseler, A. \& Minh, B. Q. 2015. IQ-TREE: a fast and effective stochastic algorithm for estimating maximum-likelihood phylogenies. Mol. Biol. Evol. 32:268-274.

Oami, K., Sibaoka, T. \& Naitoh, Y. 1988. Tentacle regulating potentials in Noctiluca miliaris: their generation sites and ionic mechanisms. J. Comp. Physiol. A 162:179-185.

Okamoto, O. K. \& Hastings, J. W. 2003. Novel dinoflagellate clock-related genes identified through microarray analysis. J. Phycol. 39:519-526.

Plattner, H. 2014. Calcium regulation in the protozoan model, Paramecium tetraurelia. J. Eukaryot. Microbiol. 61:95-114.

Pozdnyakov, I., Matantseva, O., Negulyaev, Y. \& Skarlato, S. 2014. Obtaining spheroplasts of armored dinoflagellates and first single-channel recordings of their ion channels using patch-clamping. Mar. Drugs 12:4743-4755.

Pozdnyakov, I., Matantseva, O. \& Skarlato, S. 2018. Diversity and evolution of four-domain voltage-gated cation channels of eukaryotes and their ancestral functional determinants. Sci. Rep. 8:3539.

Pozdnyakov, I., Safonov, P. \& Skarlato, S. 2020. Diversity of voltage-gated potassium channels and cyclic nucleotide-binding domain-containing channels in eukaryotes. Sci. Rep. 10:17758.

Pozdnyakov, I. \& Skarlato, S. 2012. Dinoflagellate amphiesma at different stages of the life cycle. Protistology 7:108-115.

Pozdnyakov, I. A. \& Skarlato, S. O. 2015. Analysis of the dino- flagellate Prorocentrum minimum transcriptome: identifying the members of the voltage-gated cation channel superfamily. Cell Tissue Biol. 9:483-492.

Rambaut, A. \& Drummond, A. J. 2015. FigTree, ver. 1.4. 2. The Author.

Rodriduez, J. D., Haq, S., Bachvaroff, T., Nowak, K. F., Nowak, S. J., Morgan, D., Cherny, V. V., Sapp, M. M., Bernstein, S., Bolt, A., DeCoursey, T. E., Place, A. R. \& Smith, S. M. E. 2017. Identification of a vacuolar proton channel that triggers the bioluminescent flash in dinoflagellates. PLoS ONE 12:e0171594.

Saldarriaga, J. F. \& 'Max' Taylor, F. J. R. 2017. Dinoflagellata. In Archibald, J. M., Simpson, A. G. B. \& Slamovits, C. H. (Eds.) Handbook of the Protists. Springer, Cham, pp. 625-678.

Schneider, F., Grimm, C. \& Hegemann, P. 2015. Biophysics of channelrhodopsin. Annu. Rev. Physiol. 44:167-186.

Sharma, T., Dreyer, I., Kochian, L. \& Piñeros, M. A. 2016. The ALMT family of organic acid transporters in plants and their involvement in detoxification and nutrient security. Front. Plant. Sci. 7:1488.

Sibaoka, T. \& Eckert, R. 1967. An electrophysiological study of the tentacle-regulating potentials in Noctiluca. J. Exp. Biol. 47:447-459.

Skarlato, S. O., Telesh, I. V., Matantseva, O. V., Pozdnyakov, I. A., Berdieva, M. A., Schubert, H., Filatova, N. A., Knyazev, N. A. \& Pechkovskaya, S. A. 2018. Studies of bloom-forming dinoflagellates Prorocentrum minimum in fluctuating environment: contribution to aquatic ecology, cell biology and invasion theory. Protistology 12:113-157.

Smith, S. M. E., Morgan, D., Musset, B., Cherny, V. V., Place, A. R., Hastings, J. W. \& DeCoursey, T. E. 2011. Voltage-gated proton channel in a dinoflagellate. Proc. Natl. Acad. Sci. U. S. A. 108:18162-18167.

Stelly, N., Mauger, J. -P., Claret, M. \& Adoutte, A. 1991. Cortical alveoli of Paramecium: a vast submembranous calcium storage compartment. J. Cell Biol. 113:103-112.

Taylor, A. R., Brownlee, C. \& Wheeler, G. L. 2012. Proton channels in algae: reasons to be excited. Trends Plant Sci. 17:675-684.

Taylor, A. R., Chrachri, A., Wheeler, G., Goddard, H. \& Brownlee, C. 2011. A voltage-gated $\mathrm{H}^{+}$channel underlying $\mathrm{pH}$ homeostasis in calcifying coccolithophores. PLoS Biol. 9:e1001085.

Telesh, I., Schubert, H. \& Skarlato, S. 2021. Abiotic stability promotes dinoflagellate blooms in marine coastal ecosystems. Estuar. Coast. Shelf Sci. 251:107239.

Tikhonov, D. B. \& Zhorov, B. S. 2005. Modeling P-loops domain of sodium channel: homology with potassium channels and interaction with ligands. Biophys. J. 
88:184-197.

Tsim, S. T., Wong, J. T. \& Wong, Y. H. 1997. Calcium ion dependency and the role of inositol phosphates in melatonin-induced encystment of dinoflagellates. J. Cell Sci. 110:1387-1393.

Van Dolah, F. M., Lidie, K. B., Morey, J. S., Brunelle, S. A., Ryan, J. C., Monroe, E. A. \& Haynes, B. L. 2007. Microarray analysis of diurnal- and circadian-regulated genes in the Florida red-tide dinoflagellate Karenia brevis (Dinophyceae). J. Phycol. 43:741-752.

Wright, J. R., Amisten, S., Goodall, A. H. \& Mahaut-Smith, M. P. 2016. Transcriptomic analysis of the ion channe- lome of human platelets and megakaryocytic cell lines. Thromb. Haemost. 116:272-284.

Yazawa, M., Ferrante, C., Feng, J., Mio, K., Ogura, T., Zhang, M., Lin, P.-H., Pan, Z., Komazaki, S., Kato, K., Nishi, M., Zhao, X., Weisleder, N., Sato, C., Ma, J. \& Takeshima, H. 2007. TRIC channels essential for $\mathrm{Ca}^{2+}$ handling in intracellular stores. Nature 448:78-82.

Yu, F. H., Yarov-Yarovoy, V., Gutman, G. A. \& Catterall, W. A. 2005. Overview of molecular relationships in the voltage-gated ion channel superfamily. Pharmacol. Rev. 57:387-395. 